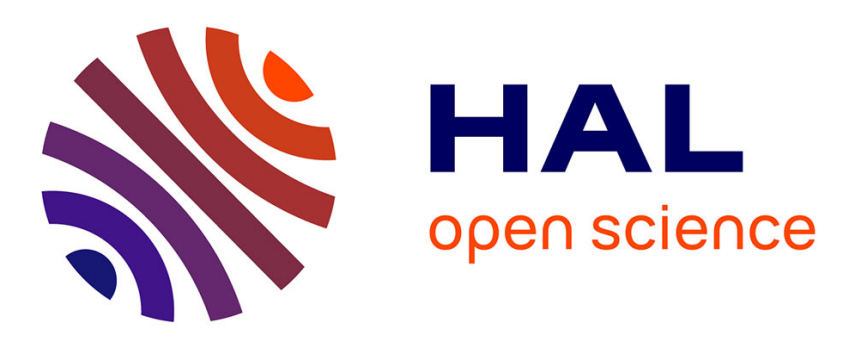

\title{
Large-scale effects of earthworms on soil organic matter and nutrient dynamics
}

\author{
Patrick Lavelle, Beto Pashanasi, Fabienne Charpentier, Cécile Gilot, \\ Jean-Pierre Rossi, Laurent Derouard, Jean André, Jean-François Ponge, \\ Nicolas Bernier
}

\section{To cite this version:}

Patrick Lavelle, Beto Pashanasi, Fabienne Charpentier, Cécile Gilot, Jean-Pierre Rossi, et al.. Largescale effects of earthworms on soil organic matter and nutrient dynamics. Edwards, C.A. Earthworm ecology, St. Lucie Press, pp.103-122, 1998. hal-00505398

\section{HAL Id: hal-00505398 \\ https://hal.science/hal-00505398}

Submitted on 27 Aug 2010

HAL is a multi-disciplinary open access archive for the deposit and dissemination of scientific research documents, whether they are published or not. The documents may come from teaching and research institutions in France or abroad, or from public or private research centers.
L'archive ouverte pluridisciplinaire HAL, est destinée au dépôt et à la diffusion de documents scientifiques de niveau recherche, publiés ou non, émanant des établissements d'enseignement et de recherche français ou étrangers, des laboratoires publics ou privés. 


\title{
Large-Scale Effects of Earthworms on Soil Organic Matter and Nutrient Dynamics
}

\author{
Patrick Lavelle, ${ }^{1}$ Beto Pashanasi, ${ }^{2}$ Fabienne Charpentier, ${ }^{1}$ Cécile Gilot, ${ }^{1}$ Jean-Pierre Rossi, ${ }^{1}$ Laurent \\ Derouard, ${ }^{1}$ Jean Andre, ${ }^{3}$ Jean-François Ponge, ${ }^{4}$ and Nicolas Bernier ${ }^{4}$ \\ ${ }^{1}$ Laboratoire d'Ecologie des Sols Tropicaux, ORSTOM, 32 rue Henri Varagnat, 93143 Bondy Cedex, France; \\ ${ }^{2}$ Estacion Experimental San Ramon, INIAA, Yurimaguas, Loreto, Peru; ${ }^{3}$ Université de Savoie, 73376-Le Bourget \\ du Lac, France; ${ }^{4}$ MNHN, 4 avenue du Petit Château, 91000 Brunoy, France
}

After 30 years of unquestioned success, agriculture is now facing important problems. In developed countries, huge increases in productivity have accompanied a severe depletion of "soil quality" in terms of resistance to erosion, organic contents, and concentrations of heavy metals and pesticide residues. In developing countries, intensification has been less successful due to socio-economical limitations. Nonetheless, traditional practices do not conserve the quality of soils: stocks of organic matter are rapidly depleted and erosion pulls fine particles out of the surface horizons. In a context of increasing population pressure, this degradation of soils results in many social and environment problems (Eswaran 1994).

A common feature to all sorts of soil degradation is the significant decrease of organic reserves and a severe depletion of soil invertebrate communities, especially earthworms (Lavelle et al. 1994).

The contribution of earthworms to processes of soil fertility has been described in several hundred papers and books (Satchell 1983; Lee 1985). As a result, there is a growing expectation from soil users for methods that protect soil fertility through an enhancement of biological processes. Earthworms may be considered as a resource for the farming system, and the management of their communities is a promising field for progress in agriculture practices. Demand for techniques making optimal use of that resource is likely to increase, but basic research is still needed to support their development.

The relationships between earthworm activities and soil properties are not thoroughly understood, 
especially at large time scales of years to decades. Most results have been obtained in small-scale laboratory or field designs that exaggerate the process(es) under study and can by no means be extrapolated readily to larger scales of time and space.

This paper synthesizes information on effects of earthworms at scales larger than one year. Earthworm behaviors that may affect these processes are detailed.

\section{EARTHWORMS AND SOIL FUNCTION: THE DRILOSPHERE CONCEPT}

At the real scale of, for example, a small tropical holder's plot, earthworm activities are only one determinant of soil fertility, and their effects are likely to be determined by factors operating at larger scales of time and space, viz. climate, edaphic properties, and the quality and amount of organic inputs (Lavelle et al. 1993). Earthworms participate in the soil functions through the drilosphere system defined as earthworms, physical structures, and the whole microbial and invertebrate community. As a result of digestion processes and creation of structures, the composition, structure, and relative importance of the drilosphere system is clearly determined by climate, soil parameters, and quality of organic inputs. Earthworms in turn influence soil microbial communities, and hence have effects on microbial processes of soil organic matter (SOM) and nutrient dynamics. They also affect the activities of other invertebrates, either by modifying their environment or through competition for feeding resources (Figure 1).

Finally, earthworms are not a homogeneous entity. They comprise several functional groups which have clearly distinct ecologies and impacts on the environment (Bouché 1977). Current classifications based on earthworm location in the soil profile and feeding resources are still too general to describe the large diversity in functions. Classifications based on impact on soil parameters might be useful.

The effects of earthworms on soil function thus depend on their interactions with a wide range of identified abiotic and biotic factors that operate at rather different scales of time and space. Furthermore, the effects produced will affect structures of different sizes, and persist for highly variable periods of time, depending on the factor(s) with which they interact. For example, it is expected that physical structures created by earthworms, as a result of their interactions with soil components, will last much longer than the flush of activity of dormant microorganisms that they have activated in their guts (Figure 2). 
Most studies have described processes at the scale of earthworm activities, typically in "microcosms", plots or small field enclosures. Results obtained in such conditions describe existing processes; however, they cannot be extrapolated directly to quantify and predict effects produced at the scale at which SOM dynamics and nutrient cycling are generally studied. One spectacular result of this approach is a huge discrepancy between the large importance that pedobiologists give to earthworms as regulators of soil physical structure and SOM dynamics, and the absence of any representation of earthworm activities in simulation models that describe SOM dynamics at scales of decades and hectares (Jenkinson and Rayner 1977; Molina et al. 1983; Parton et al. 1986).

A few papers have already described the effects of earthworms at the scale of the different biotic and abiotic parameters with which they interact, viz. (1) selection of ingested particles and digestion processes at the scale of a gut transit (0.5-20 hours) (Lee 1985; Barois and Lavelle 1986); (2) immobilization-reorganization of nutrients in fresh casts (1-20 days) (Syers et al. 1979; Lavelle et al. 1992; Lopez-Hernandez et al. 1993); (3) evolution of SOM in aging casts (3-30 months) (Martin 1991; Lavelle and Martin 1992; Blair et al. 1994). Longterm evolution of SOM at the scale of the whole soil profile and pedogenesis during periods of years to centuries has been identified, although no information was currently available (Figure 3).

This paper describes effects of earthworms on SOM and nutrient dynamics observed in three-year field experiments, and details three sub-processes that may determine the long-term effects of earthworms, i.e., feeding behaviors, patterns of horizontal distribution, and participation of earthworm activities in successional processes. Simulations of SOM dynamics, based on the CENTURY model (Parton et al. 1988), give some insight on effects to be observed at a time scale of 10-50 years.

\section{EARTHWORM BEHAVIOR}

Earthworm behavior may affect the soil function significantly. A major difference between short-scale experiments and the real world is that earthworms have limited opportunities to choose their food and move away in confined small experiments. This probably explains why they often lose weight or die in laboratory experiments. On the other hand, the introduction of unrealistically high earthworm populations to small enclosures in the field often creates concentrations of intense activity that would not normally have occurred in the field, or that only concern microsites that are either highly dispersed in nature or infrequently visited. 


\section{Selection of Particles}

Earthworms are known to select the organic and mineral components that they ingest. As a result, their casts often have much higher contents of SOM and nutrients than the surrounding soil (Lee 1985). This is probably due to a preferential ingestion of plant residues (leaf and root litter debris) (Ferrière 1980; Piearce 1978; Kanyonyo 1984) and clay minerals. Barois and Patron (1994) demonstrated that the tropical peregrine species, Pontoscolex corethrurus, was able to select large organic debris and small mineral particles depending on soil type. Selection was made on aggregates rather than primary particles. There is evidence that some endogeic earthworms ingest only aggregates that do not exceed the diameter of their mouths, whereas other species may feed on large aggregates and split them into smaller aggregates (Blanchart 1990; Derouard 1993). The feeding behavior that allows such a selection has never been described in detail. The long-term consequences of that behavior, for dynamics of soil processes and SOM dynamics, have also not been directly addressed. Endogeic earthworms may deposit 20-200 $\mathrm{t}$ dry soil ha ${ }^{-1}$ surface casts that contain a significant proportion of SOM yearly. A much larger quantity of casts is deposited inside the soil and a volume of soil equivalent to the whole soil of the upper horizons may be passed through earthworm guts in a few years (Lavelle 1978). Nonetheless, the higher concentration of fine elements in casts than in the bulk soil suggests that earthworms may possibly reingest the same soil several times, while microsites with a relatively coarser texture may be avoided by earthworms.

\section{Spatial Patterns of Horizontal Distribution}

Several authors have pointed out the aggregative distribution of earthworm populations in such diverse ecosystems as an arable soil from Germany (Poier and Richter 1992), a deciduous forest of England (Phillipson et al. 1976), humid African (Lavelle 1978) and Colombian savannahs (Jimenez et al. unpub.), and an artificial pasture in southern Martinique (Rossi et al. in press). In some cases, the distribution was independent of basic soil parameters such as depth, clay, or carbon contents. Furthermore, different species tended to have different horizontal distributions (Poier and Richter 1992); in the case of an almost mono-specific community of Polypheretima elongata in Martinique, Rossi et al. (in press) observed different distribution patterns for adults and juvenile worms. These observations suggest that some earthworm populations have patchy distributions with an average patch diameter of 20-40 m. Patches seem to be independent of soil parameters to some extent. The 
dynamics of earthworm populations in a patch are not synchronized with the populations of other patches. The occurrence of such patterns suggests that earthworm activities concentrate on patches probably for limited periods of time before becoming locally extinct. At Lamto, complementary patterns have been observed between large species that accumulate large casts and tend to compact the soil and smaller species that produce fine granular casts out of large casts of the first type of species that they ingest with root litter (Blanchart 1990). In that case, the observed patterns suggest a succession of patches made of "compacting" and "decompacting" species with complementary effects on soils (Blanchart et al. in press).

\section{Compacting vs. Decompacting Species}

The physical structure of earthworm casts is highly relevant to the dynamics of SOM at intermediate scales of months to years. Two different types of casts may be distinguished in this respect, viz. the globular casts of "compacting" species and the granular casts of "decompacting" species. Casts of the first category may be surrounded by a thin 10-20-mll-cortex made of clay minerals and organic particles which seem to reduce aeration and hence inhibit microbial activity at the scale of weeks to months (Blanchart et al. 1993; Martin 1991). Soils colonized by monospecific communities of such earthworm species are prone to compaction. In an experiment where the earthworm Millsonia anomala had been introduced into a yam and a maize culture, the proportion of large aggregates $>2 \mathrm{~mm}$ increased significantly in soils that had been previously sieved, but no significant effect was observed in a soil that had kept its original structure (Table 1). Bulk density was increased significantly in both situations. Similar effects have been observed after inoculation of the peregrine, pantropical endogeic species P. corethrurus into a traditional cropping system of Peruvian Amazonia. After six successive crops, earthworms had increased the proportion of macro-aggregates (>2 mm) significantly from 25.4 to $31.2 \%$ at the expense of smaller $(<0.5 \mathrm{~mm})$ ones whose proportion had decreased from $35.4 \%$ to $27.4 \%$. Changes in soil aggregation resulted in a slight increase of bulk density (significant during the first three cropping cycles) and a significant decrease of infiltration rates and sorptivity, the latter decreasing from $0.34 \mathrm{~cm} \mathrm{sec}^{-1 / 2}$ in noninoculated treatments to $0.15 \mathrm{~cm} \mathrm{sec}^{-1 / 2}$ in treatments inoculated with $36 \mathrm{~g} \mathrm{~m}^{-2}$ fresh mass of earthworms (Alegre et al. 1996). This transformation of soil physical properties eventually resulted in changes in the soil water regime, since soil tended to be drier during dry periods and wetter in periods of heavy rainfall than in the noninoculated treatment. 
Other endogeic earthworm species have opposite effects since they tend to break down large $(>0.5 \mathrm{~mm})$ aggregates and split them into smaller ones (Blanchart 1990; Derouard et al. in press). In Western African savannahs, for example, small species of the Eudrilidae family have such abilities, and it has been hypothesized that soil aggregation is regulated by the opposite effects of large "compacting" species like, for example, Millsonia anomala and "decompacting" species like the comnon eudrilid Hyperiodrilus africanus.

These results contrast with a rather broad set of results suggesting that earthworm activities improve aeration of soil and infiltration of water (review in Lee 1985). Three hypotheses may explain such discrepancies: (1) Most studies on relationships between earthworm activities and soil physical parameters have been on Lumbricidae. This family, unlike most tropical families, comprises a large proportion of species that dig semipermanent burrows which influence water infiltration significantly. (2) In natural ecosystems the association of compacting and decompacting species may regulate soil physical properties and, in the end, favor infiltration and aeration. It is important to consider that decompacting species may belong to other taxa like Enchytraeidae (Albrecht 1984; Didden 1990; Van Vliet et al. 1993) or millipedes (Tajovsky et al. 1991). (3) The effect of Lumbricidae could be a consequence of burial of large organic particles mixed with ingested soil, since it is commonly recognized that incorporation of litter into soil has significant effects on soil physical parameters (Aina 1984; Joschko et al. 1989; Kladivko et al. 1986; Kooistra 1991; Oades 1984; Shaw and Pawluk 1986; Springett 1983; Wolters 1991).

\section{MEDIUM-TERM EFFECTS: EXPERIMENTS INOCULATING EARTHWORMS INTO CROPPING SYSTEMS OF THE HUMID TROPICS}

Three-year experiments have been conducted at two tropical sites, Lamto (Côte d'Ivoire) and Yurimaguas (Peru). Annual cropping systems were inoculated with endogeic earthworms and the dynamics of the system compared to non-inoculated systems for six successive crops over three years (Pashanasi et al. 1996; Gilot 1994).

At Yurimaguas, the $\mathrm{C}$ and $\mathrm{N}$ contents of soil decreased significantly with time. After six cropping cycles, the $\mathrm{C}$ contents had decreased from $16.8 \mathrm{mg} \mathrm{g}^{-1}$ to $1.36 \%$ and $1.51 \%$ respectively in systems inoculated with earthwonns and the control (Figure 4). Although systems with earthworms tended to have less C from the fourth cropping cycle on, the observed difference was not significant at the end of the experiment. Changes in $\mathrm{N}$ content during the experiment showed similar trends: $\mathrm{N}$ concentration increased initially in both treatments, as a 
result of $\mathrm{N}$ inputs following burning and incorporation of ashes to the soil. During the first three cropping cycles, $\mathrm{N}$ contents were higher in the inoculated treatments. From the fourth harvest on, $\mathrm{N}$ contents were lower in the inoculated treatments but were not significant. Earthworms did not affect soil nutrient contents for the first five cropping cycles: $\mathrm{Ca}, \mathrm{Mg}, \mathrm{K}$, and $\mathrm{P}$ contents first increased after burning and incorporation of ashes and th en decreased steadily. At the last harvest, cation contents were slightly higher in the earthworm-inoculated treatments, but the difference was significant only for K contents. Similar trends were observed for $\mathrm{pH}$ and $\mathrm{Al}$ saturation.

At Lamto, similar results were obtained. After four cropping cycles of maize, the $\mathrm{C}$ contents in the upper $10 \mathrm{~cm}$ of soil had decreased from $13.37 \mathrm{mg}$ g-l at time 0 to 9.75 and 9.64 in control and earthworminoculated treatments respectively, the difference observed between the last two treatments being insignificant. In spite of these results, there seemed to exist some differences in the quality of organic matter. Physical fractionation of SOM using the Feller (1979) method showed some evidence of a protection of coarse organic particles in the inoculated treatments (Gilot 1994). Furthermore, laboratory respirometric tests showed a significant increase in soil respiration rate where earthworms had been active (Tsakala 1994).

Experiments by Gilot (1994) showed that the effect of earthworms in protecting coarse organic fractions was significant only in soils that had been sieved previously. In this case reaggregation of soil by earthworms had positive effects on SOM protection. In soils that had not been sieved, large aggregates resulting from earthworm activities in the natural soil were conserved in "no earthworm" treatment during the three years that the experiment lasted. Therefore, the effect of protection linked to aggregation was retained although no earthworms were present.

\section{LONG-TERM EFFECTS OF EARTHWORMS: MODELING AND OBSERVATION OF SUCCESSIONAL PROCESSES}

In the absence of long-term experiments, evidence for effects of earthworms at scales from 10 to 100 years or more has been sought from modeling and the observation of time sequences in successional processes.

\section{Modeling}


Current models that describe SOM dynamics do not take into account explicitly the effects of the soil fauna. Part of the effects of soil invertebrates may be implicit, either when describing initial conditions (for example through the $\mathrm{C}: \mathrm{N}$ ratio that is influenced by their activities) or when choosing the decomposition rates of $\mathrm{C}$ pools that will actually include the overall effects of earthworms. An attempt was made to simulate the effect of earthworm activities on the three kinetically defined organic pools of the CENTURY model (Parton et al. 1988). This model, which simulates plant production and SOM dynamics in various agricultural and natural systems, considers three different SOM functional pools. A labile fraction (active SOM) has a rapid turnover and exists as live microbes and microbial products. The remaining fractions comprise SOM that is stabilized, either because it is physically protected (slow pool) or because it is chemically resistant (passive pool) to decomposition or both.

As a first step, the CENTURY model was used to simulate SOM dynamics and plant production in the savannah of Lamto (Martin and Parton unpub. data) and validated against observed values. Then the model was calibrated for this site and run to simulate $\mathrm{C}$ dynamics in earthworm casts and a control soil of the same savannah, sieved at $2 \mathrm{~mm}$. Observations made by Martin (1991) during a 450-day incubation of earthworm casts and control soil sieved at $2 \mathrm{~mm}$ were used as a reference. In the case of sieved soil, the model outputs were close to the experimental results, provided that slow soil $\mathrm{C}$ decomposition rates increased. Conversely, it was necessary to decrease the rates for both slow and active decomposition rates of soil $\mathrm{C}$ to simulate the dynamics in casts. Earthworm removal was simulated by replacing the active and slow soil $\mathrm{C}$ decomposition rates of the model with those obtained by calibration with control soil. Under these assumptions, the CENTURY model indicated that SOM would decrease by ca. $10 \%$ in 30 years, the largest proportion being lost in the slow pool that includes physically protected organic matter (Figure 5). This suggests that the slow decomposition rate of soil C may be influenced significantly by earthworm activities. This pool would comprise organic matter that binds micro-aggregates into macro-aggregates (Elliott 1986) which is generally lost during cultivations. Earthworms may, therefore, play an important role in stabilizing SOM, hence maintaining the SOM stock and soil structure in agroecosystems in the long term.

\section{Earthworm Activities and Successional Processes}

Successional processes of vegetation dynamics such as those observed in natural forests may precede, or follow, significant changes in the organic status of soils. Several examples indicate that earthworm activities during 
these successions vary significantly (Miles 1985) and may be limited to periods when organic matter that the y can digest is available. Sampling of soil invertebrates in a diachronic series of hevea plantations in the Côte d'Ivoire showed great changes in soil faunal communities as plantations aged (Gilot et al. 1995). During the early stages of the succession, soil faunal communities were dominated by termites, especially xylophagous species. After a few years, the abundance of this group of termites declined and other groups dominated the termite communities. After 20 years, earthworms became dominant; mesohumic and endogeic categories prevailed. Finally, in a 30-year plantation, soil faunal abundance decreased steadily, as did the production of hevea. It has been suggested that these changes could reflect successions in soil fauna communities following changes of the quality and quantity of organic matter. When the plantations were created, woody material from the primary forest was left at the soil surface. Xylophagous termites were the first invertebrate group that used this resource. They transformed decaying wood into fecal pellets that may have been used by other groups of termites and surface-living earthworms. Eventually, fecal pellets of humivorous termites may have been incorporated into the soil and been used as food by endogeic mesohumic and oligohumic species of earthworms. Once organic matter from the wood had passed through this food chain and lost most of the energy stored as carbon compounds, the food resource base for soil faunal communities was reduced to the plant residues currently available in the hevea plantation and their populations decreased drastically. Interestingly, this sharp decrease in numbers coincided with a reduction in production of hevea. These observations suggest that soil fauna, and especially earthworms, may at some stages use carbon sources that had been previously stored in the ecosystem at different stages of natural or artificial successional processes. In case of the hevea plantation, it is hypothesized that soil faunal activities are sustained, at least partly, by the energy progressively released from the decaying logs, with positive effects on hevea production.

The hypothesis that earthworm activities may develop at a determined stage in plant successions is supported by observations of Bernier et al. (1993) in an alpine forest of France located at a 1550-m elevation. In a succession of forest patches from 10 to 190 years old, significant changes in earthworm communities were observed (Figure 6). In the early stages, earthworm density was high with a clear dominance of endogeic populations. Density decreased steadily during the following 20 years and, after 60 years, when the forest was mature, earthworm populations started to increase again, although their density was low. These population changes coincided with clear changes in the amounts and quality of organic matter stored in the humus layers. The proportion of organic matter bounded to minerals, i.e., organic matter that has been mixed into the soil by 
earthworm activities, was greatest at 10 years and then decreased steadily, being almost absent after 60 years (Figure 7). In the late stages of succession, bound organic matter resumed accumulation. The pattern of changes with time of unbound organic matter was exactly opposite to that of bound organic matter. The amount of unbound organic matter decreased when earthworms were abundant, and increased when their populations were at low densities. This is evidence that during the cycle of growth, maturation, and senescence of the forest, humus type changed with a maximum development of a moder at 60 years and a mull at 10 years. It is hypothesized that a forest accumulates organic matter as litter and raw humus during the early phases of growth, when primary production is high. Then earthworm populations start to develop at the expense of these organic accumulations, and they progressively incorporate the non-digested part of this raw organic matter into organomineral complexes (Figure 7). This process results in the release of large amounts of nutrients and the creation of physical structures (macro-aggregates, macropores, and galleries) typical of a mull type humus. This medium is believed to be favorable for the establishment and growth of seedlings. Processes whereby earthworm populations establish and the reason why earthworms become able to live in what was previously an acid environment have not yet been identified.

\section{DISCUSSION}

The long-term effects of earthworms on SOM dynamics vary depending on the scale of time considered. When earthworms are introduced artificially into an ecosystem, they use part of the $\mathrm{C}$ resources for their activities. In the African savannahs of Lamto (Côte d'Ivoire), the amount of $\mathrm{C}$ mineralized directly through earthworm respiration was estimated as $1.2 \mathrm{t} \mathrm{Cha}^{-1} \mathrm{year}^{-1}$ in a grass savannah, which is equivalent to about $5 \%$ of primary production (Lavelle 1978). The annual average population densities and biomass were 202 individuals and 39.7 $\mathrm{g} \mathrm{m}^{-2}$ respectively, and this population ingested up to 1000-1250 $\mathrm{t}$ dry soil ha ${ }^{-1}$ year $^{-1}$. As part of this process, nutrients were released and made available to plants or microorganisms. In the same savannah, the overall amount of assimilable $\mathrm{N}$ released as ammonium in feces, or labile organic $\mathrm{N}$ in dead worms, and mucus has been estimated at 21.1 to $38.6 \mathrm{~kg} / \mathrm{ha} / \mathrm{yr}$ of $\mathrm{NH}_{4}-\mathrm{N}$ in a population of Millsonia anomala that comprises $60 \%$ of the population biomass. The overall production of mineral-N for the earthworm community is therefore expected to range from 30 to $50 \mathrm{~kg}$. In tropical pastures, with earthworù biomasses of $1-3 \mathrm{t} \mathrm{ha}^{-1}$ and soils with higher 
contents in organic nitrogen, the contribution of earthworms to $\mathrm{N}$-mineralization may probably reach a few hundred $\mathrm{kg}$ mineral-N ha ${ }^{-1} \mathrm{year}^{-1}$. In temperate pastures, the flux of mineral-N from earthworms may be estimated at a few hundred $\mathrm{kg} \mathrm{ha}^{-1}$ year $^{-1}$ (Syers et al. 1979; Hameed et al. 1994). Similar processes have been observed regarding $\mathrm{P}$, but no real estimates of amounts released $\mathrm{ha}^{-1} \mathrm{year}^{-1}$ have been produced (Sharpley and Syers 1976; Lopez-Hernandez et al. 1993; Brossard et al. 1994). There is some evidence that plants may accumulate these nutrients but the exact proportion, especially on a yearly basis, is not known (Spain et al. 1992; Hameed et al. 1994).

Increased nutrient turnover from earthworm activities usually results in increased plant growth. Most experiments on the scale of one to six successive cropping cycles show significant effects of earthworm activities on plant production; these effects seem to be proportional to earthworm biomass, within a limited range of biomass (Lavelle 1994). Whether this increased production is sustained in the long term is not known. On the one hand, earthworms tend to feed on existing stocks of almost undecomposed organic matter and accelerate their decomposition. Once these stocks are depleted, earthworm activities may cease, and the system will return to lower levels of plant production. Observations made in rubber plantations of different ages in Côte d'Ivoire seem to support this hypothesis (Gilot et al. 1995). Observations of successional processes in an alpine spruce forest of France showed that earthworm activities seem to have been reduced by the accumulation of lowquality litter residues that they could not process, rather than by the exhaustion of available organic resources. In that case, spruce litter may have become palatable only after a long period of maturation during which fungal attacks progressively eliminated those toxic compounds present in fresh litter. The effect of litter quality on earthworm activities has already been stressed in studies on Finnish spruce forests where the input of highquality litter allowed earthworm populations to increase significantly in an acid environment (Huhta 1979).

However, earthworms may participate in the accumulation of organic matter through (1) an increase of organic matter produced in the ecosystem and (2) the protection of SOM in structures of the drilosphere (Martin 1991). In the threeyear experiment carried on at Yurimaguas and Lamto, the combination of $\mathrm{C}$ consumption by inoculated earthworms and increased capture of C by plants and protection of SOM in compact casts did not together result in significant changes in the abundance of C. Nevertheless, there were clear indications that the quality of organic matter estimated by either physical fractionation or respirometry was modified. Consequences of such long-term modifications are not predictable yet. 
Physical effects resulting from earthworm activities seem to persist for long periods in soils. Blanchart et al. (1993) demonstrated that casts deposited by large earthworms (of the "compacting" category) had largely kept their structure 30 months after earthworms had disappeared. These casts tend to conserve organic matter, because little microbial activity is possible in these compact structures. Nonetheless, in natural conditions, such macro-aggregates cannot comprise more than $40 \%$ to $60 \%$ of soil. Despite their continuous production these aggregates do not accumulate beyond that limit, probably because earthworm populations that decompact soil regulate aggregation. These may be earthworms such as the small species of Eudrilidae at Lamto. They may also be species of Enchytraeidae, Myriapoda, or microarthropods. Therefore, the long-term efficiency of these processes of protection of aggregates in casts largely depends on (1) the maximum percentage of large aggregates that are present at a given site and (2) the lifetime of aggregates.

Spatial patterns of earthworm populations may be understood best in terms of their impact on soils. At Lamto, there was a significant negative correlation at some seasons between populations of compacting species that accumulate large compact casts in the upper $20 \mathrm{~cm}$ of soil, and decompacting species that produce fine granular-shaped casts out of soil macro-aggregates and the large casts produced by the former species (I.P. Rossi and P. Lavelle, unpub. after Lavelle 1978). This may indicate that earthworm sub-population experiments have successions inside a patch. Species that compact soils develop once those that decompact soils have produced small aggregates rich in the organic matter that the compacting species may ingest. Such patterns may also be determined by the local availability of assimilable organic matter. Studies in hevea plantations and spruce forests show clearly that the impact of earthworms becomes important when organic matter has been sufficiently prepared by a succession of termite and arthropod digestions in the first case and development of fungal attacks in the second one.

These results and hypotheses open several avenues for future research as follows:

(1) Testing the effect of earthworm activities on quality of soil organic matter (through physical fractionations and respirometry) in long-term experiments using natural $13 \mathrm{C}$ labeling after, for example, a change from $\mathrm{C} 3$ to $\mathrm{C} 4$ vegetation;

(2) Establishment of carbon budgets to quantify the amount of C derived to earthworms and identify the pools in which this $\mathrm{C}$ is taken;

(3) Experiments on the effects of the addition of organic matter, of different physical and chemical 
qualities, on earthworm activities. This last research theme has clear practical implications, since what is envisaged is the improvement of earthworm activities in agricultural systems with a view to increasing crop production and soil sustainability.

\section{REFERENCES CITED}

Aina, P.O. 1984. Contribution of earthworms to porosity and water infiltration in a tropical soil under forest and long-term cultivation. Pedobiologia, 26, 131-136.

Albrecht, A. 1984. Role des Enchytraeidae dans l'agrégation et l'humification d'humus de type moder de l'Est de la France. Thèse de Doctorat. Nancy 1.

Alegre, 1, B. Pashanasi, and P. Lavelle. 1996. Dynamics of soil physical properties in a low input agricultural system inoculated with the earthworm Pontoscolex corethrurus in Peruvian Amazonia. Soil Science Society of America Journal, 60, 1522-1529.

Anderson, J.M. 1994. Functional attributes of biodiversity in land use systems. In Soil Resilience and Sustainable Land Use (eds. J. Greenland and I. Szabolcs), CAB International, Wallingford, U.K., pp. 267-290.

Barois, L, and P. Lavelle. 1986. Changes in respiration rate and some physicochemical properties of a tropical soil during transit through Pontoscolex corethrurus (Glossoscolecidae, Oligochaeta). Soil Biology and Biochemistry, 18, 539-541.

Barois, L, and C. Patron. 1994. Short scale effects of tropical endogeic species: Selection of particles by Pontoscolex corethrurus. In CCE/STD Project No. ERBTS3*CT920128, pp. 33-37.

Barois, L, B. Verdier, P. Kaiser, A. Mariotti, P. Rangel, and P. Lavelle. 1987. Influence of the tropical earthworm Pontoscolex corethrurus (Glossoscoleciae) on the fixation and mineralization of nitrogen. In On Earthworms (eds. A.M. Bonvicini and P. Omodeo), Mucchi, Bologna, Italy, pp. 151 -158.

Bernier, N., J.F. Ponge, and J. Andre. 1993. Comparative study of soil organic layers in two bilberry spruce forest stands (Vaccinio-Picetea). Relation to forest dynamics. Geoderma, 59, 89-108. 
Blair, J.M., R.W. Parmelee, and P. Lavelle. 1994. Influence of earthworms on biogeochemistry in North American ecosystems. In Earthworm Ecology in Forest Rangeland and Crop Ecosystems in North America (ed. P.F. Hendrix), Lewis Publishers, Chelsea, MI, pp. 1-44.

Blanchart, E. 1990. Rôle des vers de terre dans la formation et la conservation de la structure des sols de la savane de Lamto (Côte d'Ivoire). Thèse de l'Université. Rennes 1.

Blanchart, E., A. Bruand, and P. Lavelle. 1993. The physical structure of casts of Millsonia anomala (Oligochaeta: Megascolecidae) in shrub savannah soils (Côte d'Ivoire). Geoderma, 56,119-132.

Blanchart, E., P. Lavelle, E. Braudeau, Y. Le Bissonais, and C. Valentin. 1996. Regulation of soil structure by geophagous earthworm activities in humid savannahs of Cote d'Ivoire. Soil Biology and Biochemistry, in press.

Bouché, M.B. 1977. Stratégies lombriciennes. In Soil Organism as Components of Ecosystems (eds. T. Persson and U. Lohm), Ecological Bulletins (Stockolm), 25, 122-132.

Brossard, M., P. Lavelle, and J.Y. Laurent. 1996. Digestion of a vertisol by an endogeic earthworm (Polypheretima elongata, Megascolecidae) increases soil phosphate extractibility. European Journal of Soil Biology, 32, 107-111.

Derouard, L. 1993. Effets comparés de trois espèces de vers de terre sur la structure physique d'un sol de la savane de Lamto (Côte d'Ivoire). Mémoire de DESS Gestion des Systèmes "Agro-Sylvo-Pastoraux", Paris XII.

Derouard, L., J. Tondoh, Vilcosqui, and P. Lavelle. 1997. Species-specific effects in the response of tropical annual crops to the inoculation of earthworms. Short-scale experiments at Lamto (Côte d'Ivoire). Soil Biology and Biochemistry, in press.

Didden. W.A.M. 1990. Involvement of Enchytraeidae (Oligochaeta) in soil structure evolution in agricultural fields. Biology and Fertility of Soils, 9, 152-158.

Elliott, E.T. 1986. Aggregate structure and carbon, nitrogen, and phosphorus in native and cultivated soils. Soil Science Society of America Journal, 50, 627-633. 
Eswaran, H. 1994. Soil resilience and sustainable land management in the context of AGENDA 21. In Soil Resilience and Sustainable Land Use (eds. D.J. Greenland and I. Szabolcs), CAB International, Wallingford, U.K.

Feller, C. 1979. Une méthode de fractionnement granulométrique de la matière organique des sols: Application aux sols tropicaux à texture grossière, très pauvres en humus. Cahiers de l'O.R.S.T.O.M., Série Pédologie, XVII(4), 339-346.

Ferrière, G. 1980. Fonctions des Lombriciens. VII. Une méthode d'analyse de la matière organique végétale ingérée. Pedobiologia, 20, 263-273.

Gilot, C. 1994. Effets de l'introduction du ver géophage tropical Millsonia anomala Omodeo en systèmes cultivés sur les caractéristiques des sols et la production végétale en moyenne Côte d'Ivoire. Doctoral thesis. University of Paris VI/INAPG.

Gilot, C., P. Lavelle, Ph. Kouassi, and G. Guillaume. 1995. Biological activity of soils in Hevea stands of different ages in Côte d'Ivoire. Acta Zoologica Fennicii, 196,186-190.

Hameed, R., M.B. Bouche, and J. Cortez. 1994. Etudes in situ des transferts d'azote d'origine lombricienne (Lumbricus terrestris L.) vers les plantes. Soil Biology and Biochemistry, 26,495-501.

Huhta, V. 1979. Effects of liming and deciduous litter on earthworm (Lumbricidae) populations of a spruce forest, with an inoculation experiment on Allolobophora caliginosa. Pedobiologia, 19, 340-345.

Jenkinson, D.S., and J.H. Rayner. 1977. The turnover of soil organic matter in some of the Rothamsted classical experiments. Soil Science, 123, 298-305.

Joschko, M., H. Diestel, and O. Larink. 1989. Assessment of earthworm burrowing efficiency in compacted soil with a combination of morphological and soil physical measurements. Biology and Fertility of Soils, 8, 191-196.

Kanyonyo ka Kajondo, J.B. 1984. Ecologie alimentaire du ver de terre detritivore Millsonia lamtoiana (Acanthdrilidae, Oligochètes) dans la savane de Lamto (Côte d'Ivoire). Thèse 3è cycle. Paris VI.

Kladivko, E.J., A.D. Mackay, and J.M. Bradford. 1986. Earthworms as a factor in the reduction of soil cmsting. 
Soil Science Society of America Journal, 50, 191-196.

Kooistra, M.J. 1991. A micromorphological approach to the interactions between soil structure and soil biota. Agriculture, Ecosystems and Environment, 34, 315-328.

Lavelle, P. 1978. Les Vers de Terre de la savane de Lamto (Côte d'Ivoire): Peuplements, populations, et fonctions dans l'écosystème. Publications du Laboratoire de Zoologie de l'ENS n 12 , Paris.

Lavelle, P. 1997. Faunal activities and soil processes: Adaptive strategies that determine ecosystem function. Advances in Ecological Soil Research, 27, 93-132.

Lavelle, P., and A. Martin. 1992. Small-scale and large-scale effects of endogeic earthworms on soil organic matter dynamics in soils of the humid tropics. Soil Biology and Biochemistry, 24, 1491-1498.

Lavelle, P., G. Melendez, B. Pashanasi, and R. Schaefer. 1992. Nitrogen mineralization and reorganisation in casts of the geophagous tropical earthworm Pontoscolex coretlntrus (Glossoscolecidae). Biology and Fertility of Soils, 14, 49-53.

Lavelle, P., E. Blanchart, A. Martin, S. Martin, I. Barois, F. Toutain, A. Spain, and R. Schaefer. 1993. A hierarchical model for decomposition in terrestrial ecosystems. Application to soils in the humid tropics. Biotropica, 25, 130-150.

Lavelle, P., M. Dangerfield, C. Fragoso, V. Eschenbrenner, D. Lopez-Hemandez, B. Pashanasi, and L. Bmssaard. 1994. The relationship between soil macrofauna and tropical soil fertility. In The Biological Management of Tropical Soil (eds. M.J. Swift and P. Woomer), John Wiley-Sayce, New York, pp. 137169.

Lee, K.E. 1985. Earthworms: Their Ecology and Relationships with Soils and Land Use. Academic Press, New York.

Lopez-Hemandez, D., J.C. Fardeau, and P. Lavelle. 1993. Phosphorus transformations in two P-sorption contrasting tropical soils during transit through Pontoscolex corethrurus (Glossoscolecidae, Oligochaeta). Soil Biology and Biochemistry, 25, 789-792.

Martin, A. 1991. Short-and long-term effects of the endogeic earthworm Millsonia anomala (Omodeo) 
(Megascolecidae, Oligochaeta) of tropical savannas on soil organic matter. Biology and Fertility of Soils, Il, 234-238.

Miles, J. 1985. Soil in the ecosystem. In Ecological Interactions in Soil; Plants, Microbes and Animais (eds. D. Atkinson, A.H. Fitter, DJ. Read, and M.B. Usher), Blackwell Scientific Publications, Oxford, Great Britain, pp. 407-427.

Molina, J.A.E., C.E. Clapp, M.J. Shaffer, F.W. Chichester, and W.E. Larson. 1983. NCSOIL, a model of C and $\mathrm{N}$ transformations in soils: Description, calibration and behaviour. Soil Science Society of America Journal, 47, 85-91.

Oades, J.M. 1984. Soil organic matter and structural stability: Mechanisms and implication for management. Plant and Soil, 76, 319-337.

Parton, W.J., D.W. Anderson, C.V. Cole, and J.W.B. Stewart. 1983. Simulation of soil organic matter fonnation and mineralization in semiarid agroecosystems. In Nutrient Cycling in Agricultural Ecosystems (eds. R.R. Lowrance, R.L. Todd, L.E. Asmussen, and R.A. Leonard), Special Publication No. 23 of the Georgia Experimental Station, Athens, Georgia.

Parton, W.J., J.W.B. Stewart, and C.V. Cole. 1988. Dynamics of C, N, P and S in grasslands soils: A model. Biogeochemistry, 5, 109-131.

Pashanasi, B., P. Lavelle, and J. Alegre. 1996. Effect of inoculation with the endogeic earthworm Pontocolex corethrurus on soil chemical characteristics and plant growth in a low input agricultural system of Peruvian Amazonia. Soil Biology and Biochemistry, 28, 801 -810.

Phillipson, J., R. Abel, 1 Steel, and S.R. Woodell. 1976. Earthworms and the factors that govern their distribution. Oecologia, 33, 291-309.

Piearce, T.G. 1978. Gut contents of some lumbricid earthworms. Pedobiologia, 18, 3-157.

Poier, K.R., and J. Richter. 1992. Spatial distribution of earthworms and soil properties in an arable loess soil. Soil Biology and Biochemistry, 24, 1601-1608.

Rossi, J.P., P. Lavelle, and A. Albrecht. 1997. Relationships between spatial pattern of the endogeic earthworm 
Polypheretùna elongata and soil heterogeneity in a tropical pasture of Martinique (French West Indies). Soil Biology and Biochemistry, in press.

Sharpley, A.N., and J.K Syers. 1976. Potential role of earthworm casts for the phosphorus enrichment of run-off waters. Soil Biology and Biochemistry, 8,341-346.

Shaw, C., and S. Pawluk. 1986. The development of soil structure by Octolasion tyrtaeum, Aporrectodea turgida and Lumbricus terrestris in parent materials belonging to different textural classes. Pedobiologia, 29, 327-339.

Spain, A.V., P. Lavelle, and A. Mariotti. 1992. Stimulation of plant growth by tropical earthworms. Soil Biology and Biochemistry, 24, 1629-1634.

Springett, J.A. 1983. Effect of five species of earthworm on some soil properties. Journal of Applied Ecology, $20,865-872$.

Syers, J.K, A.N. Sharpley, and D.R. Keeney. 1979. Cycling of nitrogen by surface-casting earthworms in a pasture ecosystem. Soil Biology and Biochemistry, 11, $181-185$.

Tajovsky, K, G. Villemin, and F. Toutain. 1991 . Microstructural and ultrastructural changes of the oak leaf litter consumed by millipede Glomeris hexasticha (Diplopoda). Revue d'Ecologie et de Biologie du Sol, 28, 287-302.

Tsakala, R. 1994. Evolution spatio-temporelle de la minéralisation du carbone et de l'azote dans les sols de deux parcelles à Lamto (Côte d'Ivoire). Mémoire DESS, Université Paris XII, 58 pp.

Van Vliet, P.C.J., L.T. West, P.F. Hendrix, and D.C. Coleman. 1993. The influence of Enchytraeidae (Oligochaeta) on the soil porosity of small microcosms. Geoderma, 56, 287-299.

Wolters, V. 1991. Soil invertebrates: effects on nutrient turnover and soil structure. A review. Z. Pflanzenernähr Bodenk, 154, 389-402. 


\section{Legends of figures}

Figure 1. Relationships of earthworms and other soil "ecosystem engineers" with other soil biological components. Earthworms partly influence the occurrence and activity of other soil organisms since they create large structures that may persist over significant periods and affect the environment (Lavelle 1994).

Figure 2. Effects of earthworm activities on soil processes operating at different scales.

Figure 3. Effects of earthworm activities on soil organic matter dynamics at different scales of time and space.

Figure 4. Changes in $\mathrm{C}$ and $\mathrm{N}$ contents in an ultisol of Peruvian Amazonia submitted to traditional slash and burn agriculture in the presence and absence of earthworms (Pontoscolex corethrurus) (Pashanasi et al. 1996). Pairs of data with different letters are significantly different.

Figure 5. Changes of $\mathrm{C}$ contents in soils of a grass savanna at Lamto (Côte d'Ivoire) in the presence and absence of endogeic earthworms; results of a simulation using the CENTURY model (A. Martin and W.J. Parton unpub. data).

Figure 6. Changes in the abundance of earthworms of different ecological categories along a succession in an alpine spruce forest (Bernier et al. 1993).

Figure 7. Changes in the abundance of organic matter bounded to soil minerals, and unbounded organic matter along a succession in an alpine spruce forest (Bernier et al. 1994). 
Table 1. Effects of inoculation of the earthworm Millsonia anomala into cropping systems on bulk density and aggregation of soil

\begin{tabular}{|c|c|c|c|c|c|}
\hline & \multicolumn{5}{|c|}{ Crop } \\
\hline & \multicolumn{2}{|c|}{ Bulk Density } & \multicolumn{3}{|c|}{$\%$ Aggregates $>2 \mathrm{~mm}$} \\
\hline & $\begin{array}{l}\text { Maize 0-10 } \\
\mathrm{cm}\end{array}$ & $\begin{array}{l}\text { Maize 0-10 } \\
\mathrm{cm}\end{array}$ & $\begin{array}{l}\text { Yam Mounds } \\
\text { sieved soil }\end{array}$ & $\begin{array}{l}\text { Maize } 0-10 \mathrm{~cm} \\
\text { undisturbed soil }\end{array}$ & $\begin{array}{l}\text { Maize } 0-10 \mathrm{~cm} \\
\text { sieved soil }\end{array}$ \\
\hline Time (months) & 3 & 36 & 34 & 36 & 36 \\
\hline Inoculated & 1.31 & 1.48 & 53.5 & 42.5 & 42.2 \\
\hline Non-inoc. & 1.24 & 1.37 & 29.8 & 38.8 & 24.6 \\
\hline $\mathrm{P}$ & 0.06 & $<0.001$ & $<0.05$ & n.s. & $<0.01$ \\
\hline
\end{tabular}




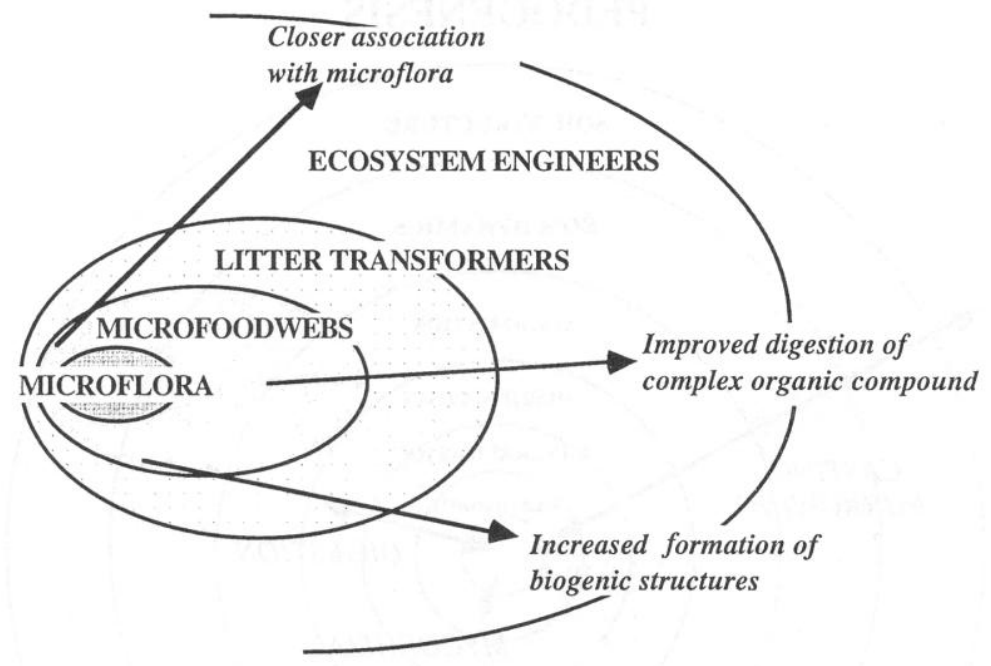

Fig. 1 


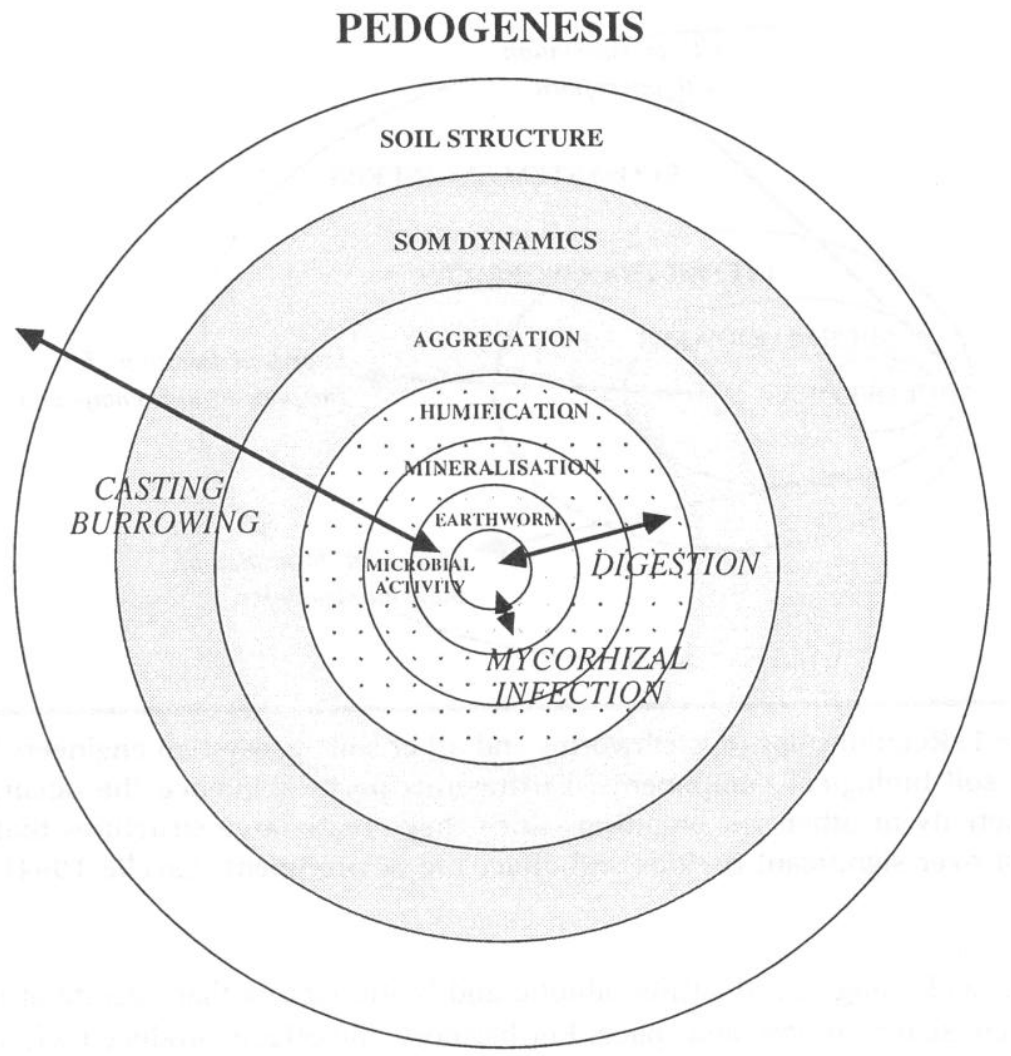

Fig. 2 


$\begin{aligned} & \text { Time } \\ & \text { Structure }\end{aligned}$
GUT CONTENT $\begin{aligned} & \text { DAYS / WEEKS } \\ & \text { FRESH CASTS }\end{aligned}$

Fig. 3 

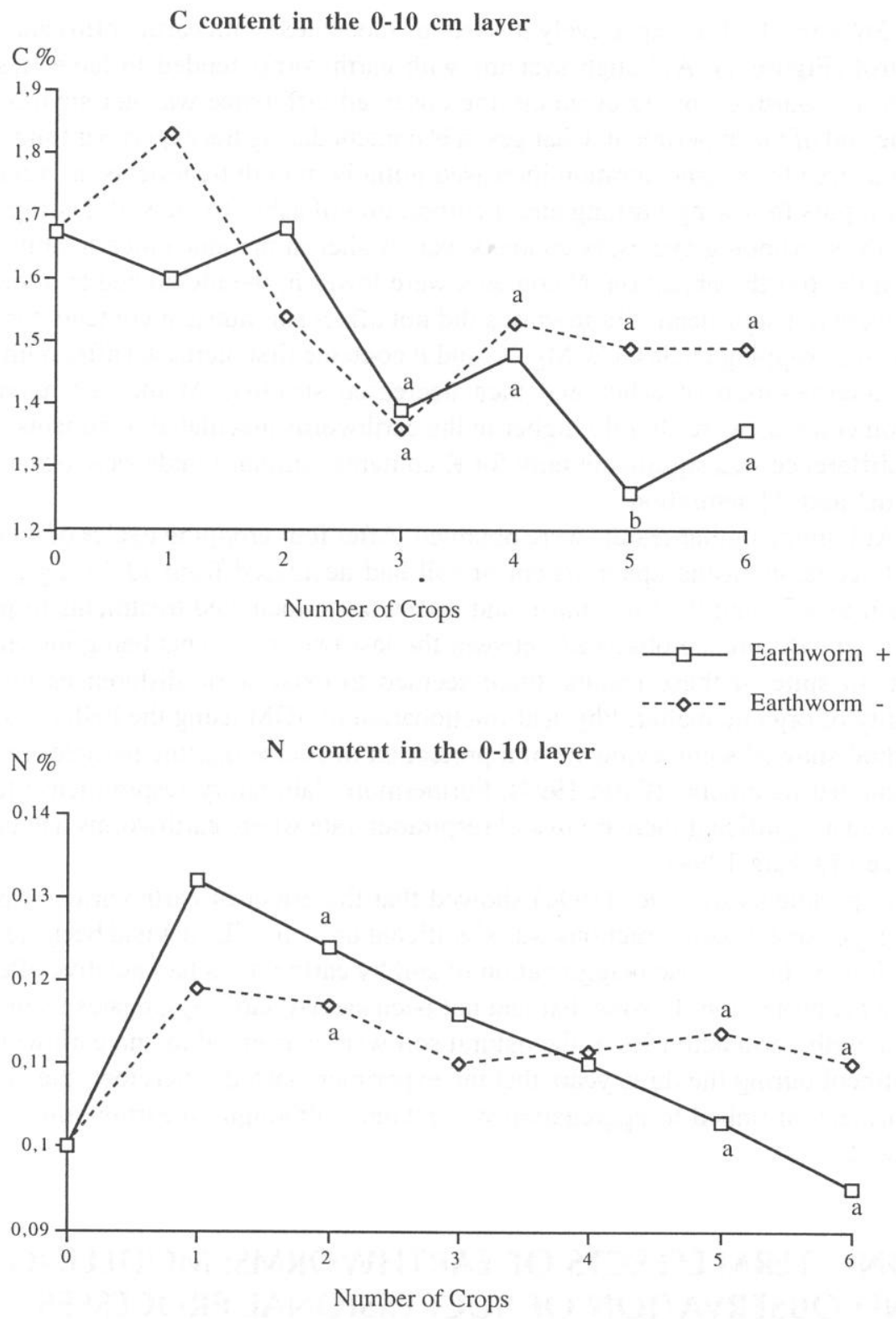

Fig. 4 
Evolution of soil $\mathrm{C}$ content in a grass savanna with or without earthworms

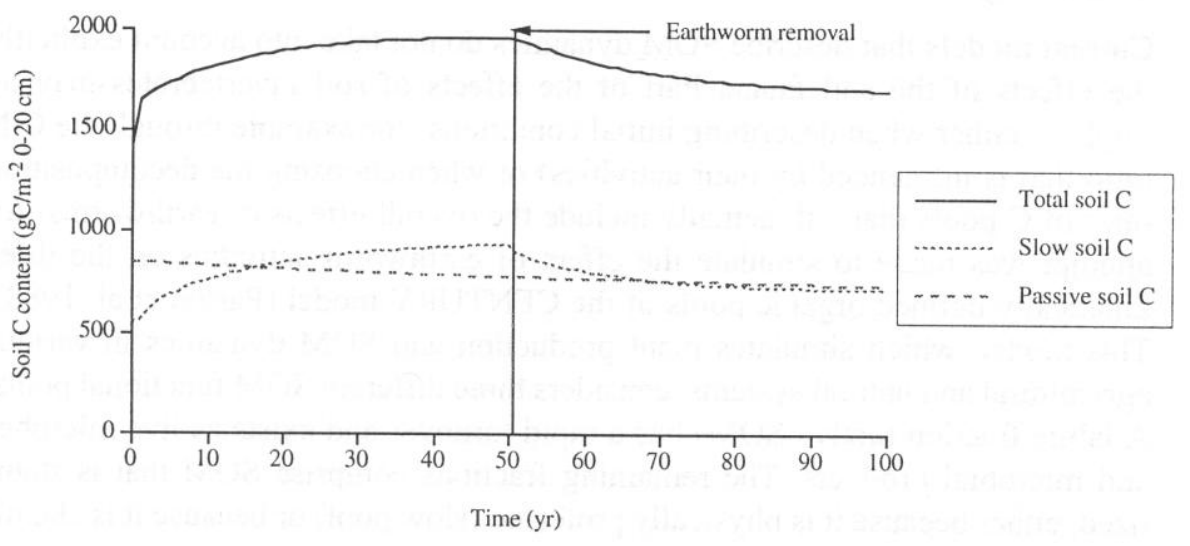

Fig. 5 


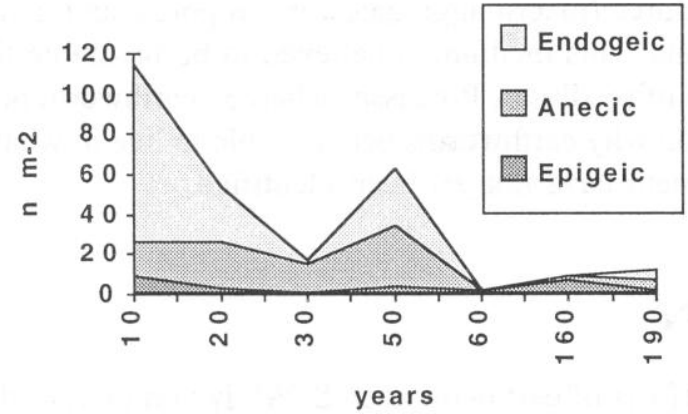

Fig. 6 


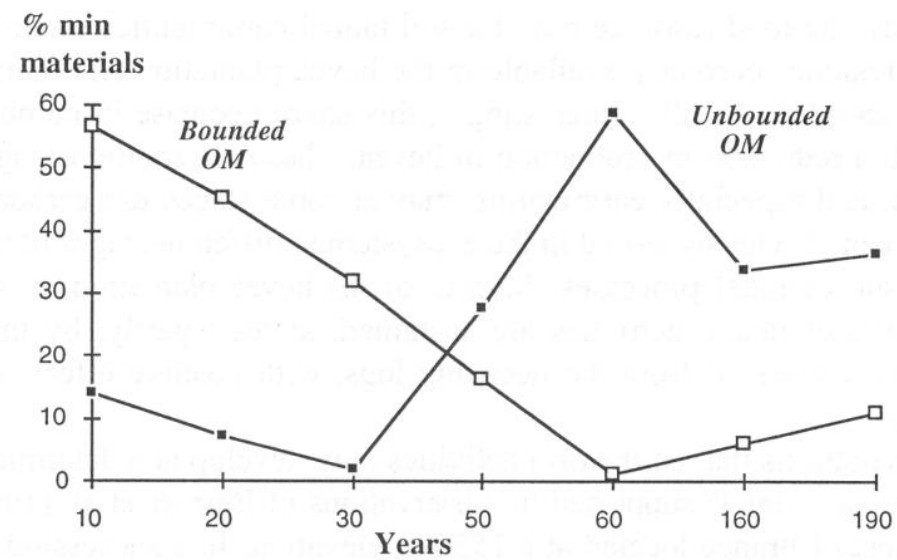

Fig. 7 